\title{
Nederlandse preventie-uitgaven onder de loep
}

\author{
Paul F. van Gils · Anita W.M. Suijkerbuijk · Johan J. Polder · G. Ardine de Wit · Marc Koopmanschap
}

Published online: 29 April 2020

(c) The Author(s) 2020

\begin{abstract}
Samenvatting
Inleiding We hebben berekend hoeveel er in 2015 aan preventie is uitgegeven. We maakten onderscheid tussen gezondheidsbescherming, gezondheidsbevordering en ziektepreventie. Bij de berekening van de uitgaven beperkten we ons tot universele, selectieve en geïndiceerde preventie. Zorggerelateerde preventie kan nauwelijks onderscheiden worden van curatieve zorg. De uitgaven aan preventie zijn berekend vanuit een maatschappelijk perspectief.

Methode We hebben gevarieerde bronnen gebruikt om de uitgaven aan preventie te onderzoeken. Voor zover de kosten onderdeel waren van de uitgaven aan zorg zijn de berekeningen gebaseerd op de gegevens van het CBS. Voor het overige is gebruikgemaakt van jaarrapporten en jaarrekeningen van ministeries en andere organisaties. Ook uitgaven van consumenten,
\end{abstract}

Digitaal aanvullende content De online versie van dit artikel (https://doi.org/10.1007/s12508-020-00258-8) bevat aanvullend materiaal, toegankelijk voor daartoe geautoriseerde gebruikers.

Dr. P. van Gils $(\bowtie) \cdot$ Dr. A. Suijkerbuijk · Prof. Dr. J. Polder G. de Wit · M. Koopmanschap

Rijksinstituut voor Volksgezondheid en Milieu, Bilthoven, Nederland

paul.van.gils@rivm.nl

Prof. Dr. J. Polder

Tranzo, School of Social and Behavioral Sciences, Tilburg University, Tilburg, Nederland

\section{G. de Wit}

Julius Center for Health Sciences and Primary Care, University Medical Center Utrecht, Utrecht University, Utrecht, Nederland

\section{Koopmanschap}

Erasmus School of Health Policy and Management, Erasmus

University Rotterdam, Rotterdam, Nederland het bedrijfsleven, ngo's en verzekeringsmaatschappijen zijn opgenomen.

Resultaten In 2015 werd 12,5 miljard euro (1,8\% van het bruto binnenlands product) uitgegeven aan preventie: 2,4 miljard aan ziektepreventie (18,8\%), 0,6 miljard aan gezondheidsbevordering (5,2\%) en 9,5 miljard aan gezondheidsbescherming (76\%). Dit is $17 \%$ minder dan er in 2007 is uitgegeven, het laatste jaar dat een dergelijk onderzoek is uitgevoerd.

Conclusie De uitgaven aan preventie zijn relatief laag vergeleken met de totale uitgaven aan zorg. Het grootste gedeelte gaat naar gezondheidsbescherming. In de komende jaren is er mogelijk een stijging aan uitgaven voor gezondheidsbevordering door regeringsbeleid, zoals het Nationaal Preventieakkoord.

Trefwoorden preventie - gezondheidsbevordering • gezondheidsbescherming · ziektepreventie · uitgaven

\section{Dutch prevention expenditure under the microscope}
Abstract
Introduction In this study we estimated national ex- penditure on prevention in 2015. A distinction was made between health protection, health promotion and disease prevention. In the estimation of preven- tion expenditures, this study is limited to universal, selective and indicated prevention, as healthcare-re- lated prevention can hardly be distinguished from cu- rative care. This study analyzed expenditure on pre- ventive activities in the Netherlands in 2015 and took a societal perspective.
Methods We used various sources to investigate spending on prevention in 2015. Insofar as costs were part of healthcare expenditure, estimates were based on the Care Accounts of Statistics Netherlands. For the remainder, we estimated expenditure using 
annual reports and annual accounts of governments and other organizations. We included preventive activities by consumers, industry, NGOs, insurance companies, and government.

Results In 2015, an estimated $€ 12.5$ billion $(1.8 \%$ of the gross domestic product) was spent on prevention: $€ 2.4$ billion on disease prevention $(18,8 \%), € 0.6$ billion on health promotion $(5,2 \%)$ and $€ 9.5$ billion on health protection (76\%). This is a decrease of $17 \%$ compared to 2007, the last year that a similar estimate was made.

Conclusion Spending on prevention is relatively low compared to total spending on healthcare. The largest part is targeted at health protection. In the coming years there may be an increase in expenditure, due to more governmental prevention policies, such as the National Prevention Agreement.

Keywords prevention $\cdot$ health promotion $\cdot$ health protection · prevention of illness $\cdot$ expenditure

\section{Inleiding}

In 2006 verscheen het eerste RIVM-rapport over de uitgaven aan preventie, met als peiljaar 2003 [1, 2]. Een actualisering met cijfers over 2007 werd gepubliceerd in 2010 [3]. De uitgaven aan preventie bedroegen toen 13 miljard euro. Het merendeel daarvan werd besteed aan gezondheidsbescherming (ruim 10 miljard, 78\%). Aan ziektepreventie werd 2,5 miljard euro uitgegeven (19\%) en aan gezondheidsbevordering 450 miljoen euro (3\%). Sindsdien is er veel gebeurd op het gebied van preventie, zowel qua nieuwe technologische ontwikkelingen en inzichten, als qua beleid. Het werd daarom tijd om de uitgaven voor preventie te actualiseren en te vergelijken met eerdere peiljaren. We maakten een schatting van de totale uitgaven aan preventie in 2015 en beschrijven waaraan dit geld is besteed. Het betreft de uitgaven van burgers, het bedrijfsleven, verzekeraars, goede doelen, zoals gezondheidsfondsen, en de overheid. In dit artikel beschrijven we de uitgaven aan preventie en vergelijken deze met die aan zorg en behandeling in hetzelfde peiljaar, 2015, en met de uitgaven aan preventie in 2003 en 2007 . We hebben geen (statistische) analyses gedaan om de schattingen van de verschillende jaren met elkaar te vergelijken.

\section{Methode}

Preventie kent meerdere definities. Hier gaan we uit van een indeling naar gezondheidsbescherming, ziektepreventie en gezondheidsbevordering. Gezondheidsbescherming richt zich op het voorkómen van gezondheidsbedreigingen, zoals blootstelling aan gevaarlijke stoffen in de woon- en leefomgeving, schoon drinkwater, goede riolering. Om dit te bewerkstelligen wordt vooral gebruikgemaakt van wet- en regelgeving, wat bijvoorbeeld tot uiting komt in het toezicht op de voedselveiligheid. Bij ziektepreventie staat het voorkómen of het tijdig signaleren van een ziekte centraal. Veelgebruikte maatregelen zijn screening, vaccinatie en geïndiceerde medicatie bij een verhoogd risico op bijvoorbeeld hart- en vaatziekten. Gezondheidsbevordering richt zich vooral op het stimuleren en in stand houden van een gezonde leefstijl (niet roken, matig alcoholgebruik, meer bewegen) door middel van onder meer gezondheidsvoorlichting en activiteiten gericht op verandering en verbetering van de sociale en fysieke omgeving. Soms is preventie een wezenlijk onderdeel van de behandeling, zoals het voorkómen van complicaties bij chronische aandoeningen. Deze zorggerelateerde preventie is in de praktijk en in zorgregistraties nauwelijks te onderscheiden van curatieve zorg en is daarom niet meegenomen in dit onderzoek.

De uitgaven aan gezondheidsbevordering en gezondheidsbescherming worden grotendeels buiten de gezondheidszorg gemaakt en vallen buiten de definities van de zorguitgaven zoals gehanteerd in de Zorgrekeningen van het CBS en het Kosten van Ziekte-onderzoek van het RIVM. We hebben deze uitgaven via vele andere bronnen in kaart gebracht, volgens de methodiek die beschreven is in de rapportages over 2003 en 2007 [1-3]. Voor de kosten die wel onder de zorguitgaven vallen maakten we gebruik van de Zorgrekeningen van het CBS [4]. Verder hebben we rapporten, jaarverslagen, jaarrekeningen en websites van overheden en allerlei organisaties doorgenomen om de omvang van andere uitgavenposten vast te stellen. Voor aanvullende data hebben we met medewerkers van deze organisaties gesproken. Om een beeld te schetsen van de uitgaven voor heel Nederland was het soms nodig om gegevens van individuele instanties te extrapoleren naar landelijk niveau. Tot slot hebben we tijdens een expertbijeenkomst de witte vlekken in onze eerste resultaten in beeld gebracht, waarna we deze met verschillende deskundigen op het gebied van preventie hebben ingekleurd. Een uitgebreid overzicht van de geraadpleegde bronnen is te vinden op https:// www.volksgezondheidenzorg.info/ en in de online bijlage bij dit artikel (een overzicht van de uitgaven aan preventie naar preventiemethode en thema).

Ons onderzoek beoogt een zo compleet mogelijk overzicht te geven van de uitgaven aan preventie. Daarom hebben we breed naar preventieve maatregelen gezocht, zowel binnen als buiten de zorg. Dat wil zeggen dat zowel preventieve activiteiten van consumenten als preventieve activiteiten van het bedrijfsleven en de (semi-)overheid in dit onderzoek zijn meegenomen. Daarbij gold als voorwaarde dat het verbeteren, dan wel in stand houden van gezondheid het primaire doel moest zijn van de maatregel of activiteit. Dat betekent dat uitgaven aan aanleg, onderhoud en bewaking van dijken bijvoorbeeld niet zijn betrokken in het onderzoek, maar uitgaven om wegen veiliger te maken weer wel. 
Tabel 1 Uitgaven aan preventie in miljarden euro's, geïndexeerd naar het prijsniveau van 2015

\begin{tabular}{|l|l|l|l|l|l|}
\hline Jaar & Ziektepreventie & Gezondheidsbevordering & Gezondheidsbescherming & Totaal & $\%$ BBP \\
\hline 2003 & 2,4 & 0,5 & 12,2 & 15,1 & 2,5 \\
\hline 2007 & 2,9 & 0,5 & $11,6^{\text {a }}$ & 14,9 & 2,1 \\
\hline 2015 & 2,3 & 9,5 & 12,5 & 1,8 \\
\hline \multicolumn{2}{l}{${ }^{2}$ De uitgaven voor de controle op zwemwater waren in het rapport over 2007 te hoog ingeschat } & &
\end{tabular}

\section{Resultaten}

In 2015 werd aan preventie 12,5 miljard euro uitgegeven (tab. 1). Dit komt overeen met 1,8\% van het bruto binnenlands product (BBP) van dat jaar. In 2003 was dit 15,1 miljard euro (geïndexeerd naar het algemene prijspeil van 2015, 2,5\% van het BBP) en in 2007 14,9 miljard euro (2,1\% van het BBP). De uitgaven aan preventie zijn dus relatief en geleidelijk gedaald. In 2015 bedroegen de totale uitgaven aan zorg 94,4 miljard euro, overeenkomend met $13,8 \%$ van het BBP [5]. Van de 12,5 miljard euro kan 2,9 miljard euro $(3,1 \%$ van de totale zorguitgaven) aangemerkt worden als uitgaven voor ziektepreventie, met name activiteiten van GGD'en, bevolkingsonderzoeken en preventieve medicatie, zoals cholesterolverlagers.

Tabel 1 laat de resultaten zien uitgesplitst naar de verschillende onderdelen van preventie. Van de totale uitgaven aan preventie komt $18,8 \%$ ten goede aan ziektepreventie. Er is sprake van een daling in de uitgaven aan ziektepreventie vergeleken met 2007 $(-18 \%)$, die vooral veroorzaakt wordt door een afname van de uitgaven aan cholesterol- en bloeddrukverlagers, en aan de preventie rondom zwangerschap. Weliswaar zijn er meer cholesterol- en bloeddrukverlagers gebruikt, maar de prijs hiervan is sterk gedaald. Er is wel een stijging waarneembaar in de uitgaven aan infectieziektenpreventie en kankerscreening. Dit laatste komt door de landelijke invoering van het bevolkingsonderzoek voor dikkedarmkanker. Van de totale uitgaven van 12,5 miljard euro werd 647 miljoen euro uitgegeven aan gezondheidsbevordering (5,2\%). De uitgaven aan gezondheidsbevordering zijn wel gestegen vergeleken met de vorige jaren, vooral door een duidelijke toename in de uitgaven aan de preventie van gokverslaving, alcoholmisbruik, ongezonde voedselconsumptie en overgewicht, en aan privé-ongeval-

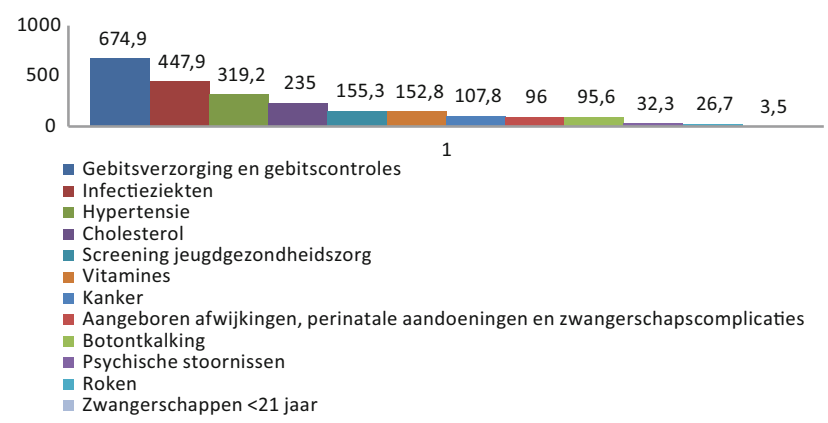

Figuur 1 Verdeling van de uitgaven aan ziektepreventie naar ziektegroepen in 2015 (in miljoenen euro's) len, met name door de inzet van buurtsportcoaches. De uitgaven aan deze posten stegen van 27,5 miljoen euro in 2007 naar 99 miljoen euro in 2015. De uitgaven aan gezondheidsbescherming zijn lager dan in het verleden vanwege een daling in de uitgaven aan verkeersveiligheid (1,1 miljard).

De fig. 1, 2 en 3 laten de verdeling in uitgaven zien naar respectievelijk ziektepreventie, gezondheidsbevordering en gezondheidsbescherming. Voor gedetailleerde informatie over de onderliggende cijfers verwijzen we naar de website www.volksgezondheidenzorg. info en naar de bijlage. Bij preventie gaat het ook om de vraag 'wie betaalt en wie profiteert'. Vandaar dat op deze site tevens wordt aangegeven wie voor de preventiemaatregel betaalt: de overheid, het bedrijfsleven, de zorgverzekeraar, de burger of een private partij, zoals een gezondheidsfonds. De imma-

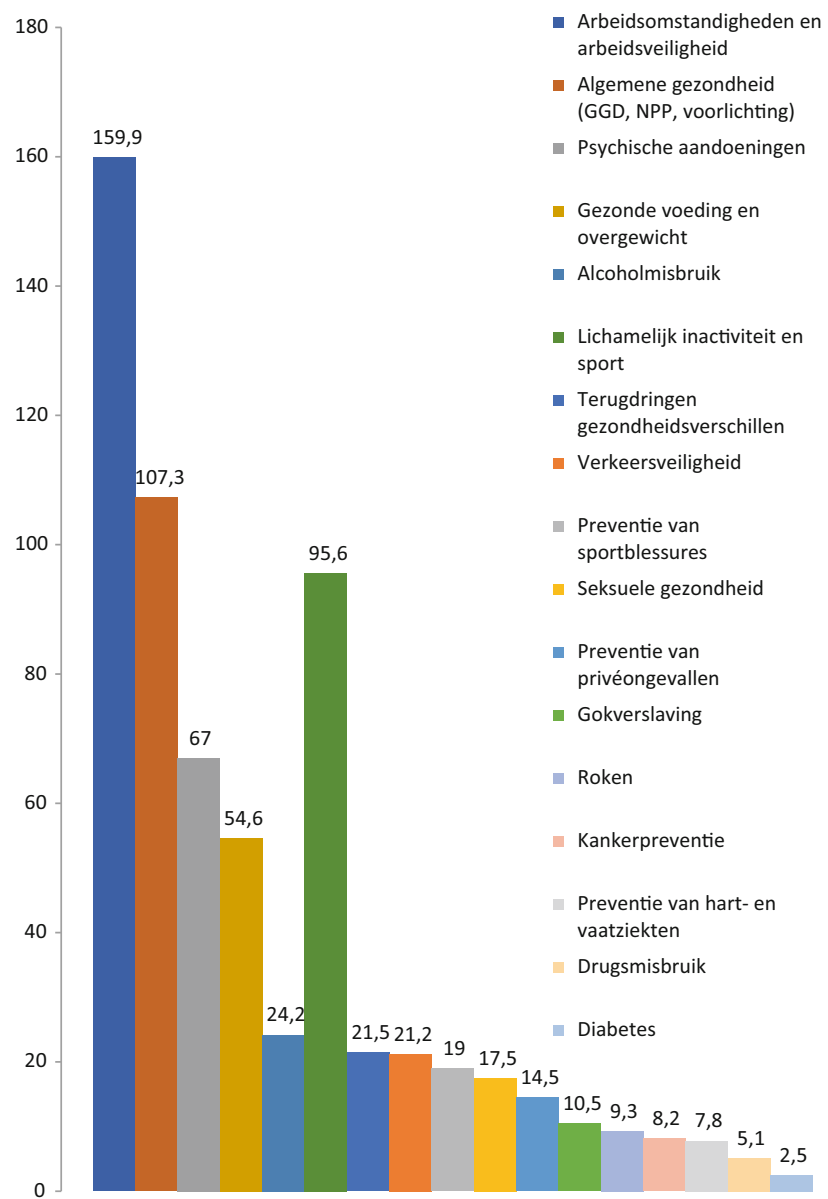

Figuur 2 Verdeling van de uitgaven aan gezondheidsbevordering in 2015 (in miljoenen euro's) 


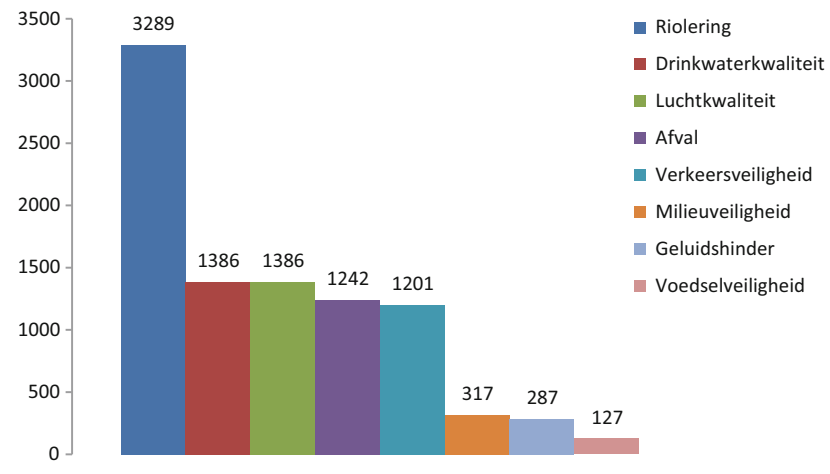

Figuur 3 Verdeling van de uitgaven aan gezondheidsbescherming in 2015 (in miljoenen euro's)

teriële opbrengsten komen uiteraard bij de samenleving terecht in de vorm van gezondheidswinst, verbetering van kwaliteit van leven en verbeterde participatie. Voor de financiën ligt dat ingewikkelder. Door investeringen van de gemeenten worden de zorguitgaven voor de zorgverzekeraars naar verwachting kleiner. Ook werkgevers profiteren van deze investeringen doordat er naar verwachting minder ziekteverzuim zal zijn. Deze geldstromen zijn niet uitgewerkt in dit overzicht. Om hier onderbouwde uitspraken over te kunnen doen zou een maatschappelijke kosten-batenanalyse (MKBA) uitgevoerd moeten worden. Een MKBA is de geëigende methode om inzichtelijk te maken welke partijen betalen en welke partijen profiteren.

\section{Conclusie}

De totale uitgaven aan preventie zijn bescheiden vergeleken met de totale zorguitgaven. Dit geldt zowel voor 2015 als voor eerdere jaren.

Preventie is hier beperkt tot activiteiten die primair gericht zijn op gezondheid. Uitgaven voor schuldhulpverlening zijn bijvoorbeeld niet meegenomen, omdat deze primair zijn bedoeld voor het oplossen van problemen rond schulden, hoewel we weten dat het oplossen van financiële problemen ook bijdraagt aan een betere psychische gezondheid. Dit geldt eveneens voor investeringen in verbeteringen in de leefbaarheid in wijken en voor investeringen in onderwijs. Ook deze investeringen zullen indirect bijdragen aan een verbeterde gezondheid van de Nederlandse bevolking. Verder is de zorggerelateerde preventie buiten beschouwing gelaten omdat deze vorm van preventie niet te scheiden is van behandeltrajecten, noch in de praktijk, noch in zorgregistraties.

De vergelijking van gezondheidsbescherming en gezondheidsbevordering brengt net als in 2003 en 2007 een belangrijk inzicht aan het licht. Nagenoeg alle activiteiten op het terrein van de gezondheidsbescherming, zoals aanleg, onderhoud en vernieuwing van riolering en het ophalen van huisafval, bestaan reeds lang en zijn een structureel onderdeel van de publieke uitgaven. Onder de vlag van gezondheids- bevordering zien we echter dat er in de verschillende peiljaren geheel verschillende activiteiten plaatsvonden en programma's werden uitgevoerd. Specifieke gezondheidsbevorderende activiteiten lijken kortdurend, projectmatig en ingegeven door actuele thema's, zoals campagnes voor meer bewegen of tegen pesten op het werk. Hoewel vaak wordt gezegd dat preventie een lange adem vergt, dat wil zeggen dat de baten van preventie pas na jaren zichtbaar worden, lijkt dit besef voor gezondheidsbevordering dus veel minder te gedeeld te worden. We hebben de kosten buiten beschouwing gelaten die gemaakt worden om een goede infrastructuur te realiseren, zodat projecten goed en effectief uitgevoerd kunnen worden. Te denken valt aan overheadkosten, zoals de loonkosten van medewerkers die zich bezighouden met gezondheidsbevordering.

De schattingen voor 2015 zijn mogelijk enigszins beïnvloed door omstandigheden als de economische stagnatie tussen 2008 en 2012. Daarbij had preventie ook een minder hoge prioriteit bij het vorige kabinet. Ook de invoering van de Wmo en Wlz, waarbij vaak decentralisatie van zorg (gepaard gaand met bezuinigingen) naar gemeenten plaatsvond, heeft mogelijk invloed gehad op de gemeentelijke preventie-uitgaven. Onze ramingen van decentrale preventie-uitgaven zijn relatief onzeker, omdat ze soms gebaseerd zijn op de uitgaven van een beperkt aantal organisaties.

Deze nuanceringen laten echter onverlet dat naar verhouding erg weinig geld wordt uitgegeven aan preventie door gezondheidsbevordering in vergelijking met gezondheidsbescherming en ziektepreventie, terwijl daar wel veel potentiële gezondheidswinst te behalen is. Bovendien laat ons onderzoek zien dat er sprake is van een behoorlijke versnippering over tal van activiteiten die vaak tijdelijk van aard zijn.

De regering heeft preventie hoog op de agenda gezet. In het Nationaal Preventieakkoord, dat vorig jaar op initiatief van Staatssecretaris Blokhuis met een groot aantal partijen is gesloten, wordt ingezet op de vermindering van roken, problematisch alcoholgebruik en overgewicht. In een brief naar de kamer schrijft de Staatsecretaris: 'Voor 2019 en 2020 is $€ 23$ miljoen en voor $2021 € 10$ miljoen vanuit het Regeerakkoord beschikbaar gesteld om acties uit het Nationaal Preventieakkoord te stimuleren. Daarnaast is er voor 2019 en 2020 een budget van $€ 6$ miljoen voor effectieve interventies. Deze preventiegelden zijn hard nodig om de meer dan 200 acties uit het akkoord te realiseren.' (https://www.parlementairemonitor.nl/ 9353000/1/j9vvij5epmj1ey0/vkzffahlulwr\#p1).

Over enkele jaren herhalen we dit onderzoek. We hopen dan antwoord te vinden op de vraag of we deze ambities op het brede terrein van preventie kunnen aflezen uit de uitgavencijfers.

Open Access This article is licensed under a Creative Commons Attribution 4.0 International License, which permits 


\section{Wetenschappelijk artikel}

use, sharing, adaptation, distribution and reproduction in any medium or format, as long as you give appropriate credit to the original author(s) and the source, provide a link to the Creative Commons licence, and indicate if changes were made. The images or other third party material in this article are included in the article's Creative Commons licence, unless indicated otherwise in a credit line to the material. If material is not included in the article's Creative Commons licence and your intended use is not permitted by statutory regulation or exceeds the permitted use, you will need to obtain permission directly from the copyright holder. To view a copy of this licence, visit http://creativecommons.org/licenses/by/4.0/.

\section{Literatuur}

1. Bekker-Grob EW de, Polder JJ, Witte KE, Mackenbach JP, Meerding WJ. Kosten van preventie in Nederland 2003. Bilthoven: RIVM; 2006.

2. Bekker-GrobEWde, PolderJJ, MackenbachJP, MeerdingWJ. Towards a comprehensive estimate of national spending on prevention. BMCPublic Health. 2007;7:252.

3. Post NAM, Bekker-Grob EW de, Mackenbach JP, Slobbe LCJ. Kosten van preventie in Nederland 2007. Bilthoven: RIVM; 2010.

4. CBS. Zorguitgaven; kerncijfers 1998-2016. 2018. https://statline.cbs.nl/Statweb/publication/?DM=SLNL\& $\mathrm{PA}=83037 \mathrm{NED}$. Geraadpleegd op 15 januari 2019.

5. RIVM. Kosten van ziekten 2015. 2018. https:// statline.rivm.nl/\#/RIVM/nl/dataset/50040NED/table? graphtype $=$ Table\&ts $=1512975518824$. Geraadpleegd op 24 januari2019. 